\title{
Green and Sustainable Finance in the Asia-Pacific Markets: An Introduction to the Special Issue
}

\author{
Toan Luu Duc Huynh ${ }^{1,2} \cdot$ Thomas Walther $^{3,4} \cdot$ Sebastian Utz ${ }^{5}$ \\ Published online: 28 February 2022 \\ (c) The Author(s), under exclusive licence to Springer Japan KK, part of Springer Nature 2022
}

\begin{abstract}
After the Paris Climate Conference in 2015, the majority of countries and sovereigns agreed to tackle the global climate changes. From finance perspectives, green and sustainable finance plays an essential role to reduce carbon emissions, to develop resilient climate infrastructure and environmental sustainability to achieve one of the sustainable goals in 2030. Among Asia-Pacific countries, million people and households, especially farmers, in the Mekong Delta of Vietnam are severely affected by droughts and saline water intrusion into their rice and fruit farming area. It might be a consequence of climate change, global warming, and construction of hydropower dams on the upper Mekong River. This is just a typical example that we stand on the brink of the climate challenges from many different sectors in the economy. We believe that the financial system has a quickly adaptive ability to adjust and develop the potential mechanisms to direct the capital flows to meet sustainable development; for example, the establishment of the green bond market or lowcarbon finance. In order to mobilize the required resources, studying 'Green and Sustainable Finance in the Asia-Pacific Markets' is a need, indeed.

While there is mounting evidence that the socio-economic factors drive the sustainable concerns (such as population in European (Pham et al., 2020), economic growth (Nasir et al., 2019), greenhouse insurance (Kosugi, 2010), there is still a need for further research about the association between financial development and
\end{abstract}

Toan Luu Duc Huynh

toanhld@ueh.edu.vn

Thomas Walther

t.walther@uu.nl

Sebastian Utz

sebastian.utz@unisg.ch

1 University of Economics Ho Chi Minh City, Ho Chi Minh City, Vietnam

2 WHU - Otto Beisheim School of Management, Vallendar, Germany

3 Utrecht University, Utrecht, The Netherlands

4 Technische Universität Dresden, Dresden, Germany

5 University of St. Gallen, St. Gallen, Switzerland 
sustainable goals. Particularly, green and sustainable investments show improved risk characteristics (Dorfleitner et al., 2020; Utz, 2018). Common questions about how green and sustainable finance could encourage investment that fosters financial institutions' commitment to cope with environmental challenges (Breitenstein et al., 2021). Against this backdrop, this special issue constitutes five high-quality original works that analyze the relationship between investments and sustainability goals as well as broader green finance and sustainable investment issues.

The first paper in the special issue investigates the relationship between foreign direct investments (FDI), renewable electricity output, and ecological footprints. The authors, Muntasir Murshed, Mohamed Elheddad, Rizwan Ahmed, Mohga Bassim, and Ei Thuzar Than assess whether globalization driven foreign investments into Bangladesh helped to foster a green energy transition and led to environmental welfare. While the authors find that FDI have a positive impact on reducing environmental footprints, they also present evidence that the general economic growth counteracts the greening of the economy. Therefore, the authors call for better measures and instruments for steering the transition and jointly foster environmental sustainability.

The second paper of the special issue is written by Theresa Schäfer and Sebastian Utz. The authors compare the financial stability of values-based banks (VBBs) and global systemically important banks (GSIBs) before and after regulatory changes in the aftermath of the financial crisis 2007. The authors' findings show that VBBs exhibit before and during the financial crisis higher levels of stability compared to GSIBs. However, after the crisis, in particular after regulatory changes affecting capital buffers and loss absorption potential, the relative difference between VBBs and GSIBs in terms of stability disappeared.

With regards to the emerging asset class of cryptocurrencies, Anh Ngoc Quang Huynh, Duy Duong, Tobias Burggraf, Hien Thi Thu Luong, and Nam Huu Bui shed some light on the link between Bitcoin's energy consumption and its returns and volume. The authors find that the impact from trading volume on energy consumption is higher in the long run than the impact of returns. Notably, the Bitcoin crash does not impede the energy consumption, which further calls for a focus on the environmental impact of cryptocurrencies.

Looking at carbon emission markets in China, Yongjie Zhang, Yue Li, and Dehua Shen, investigate the causal relationship between the risk and return in these markets and investor attention. The authors find a bidirectional causality implying that investor attention can be a helpful tool to forecast carbon market dynamics and to stimulate the carbon allowance markets.

Lastly, Chunying Wu, Xiong Xiong, and Ya Gao assess whether ESG certification can improve the price efficiency in the Chinese stock markets. Hypothesizing that ESG listed stocks signal some form of excellence, adding information, and therefore show better price efficiency compared to non-ESG-listed stocks, the authors find supportive arguments. Also listing shows an improvement while delisting appears to worsen price efficiency.

As the growing momentum of climate finance studies, this special issue aims to gather high-quality empirical and theoretical contributions which focus on the green and sustainability of financial markets in the Asia-Pacific region. The future 
direction could be extended to different geographies. Concomitantly, the green finance topics will definitely grow to cover a wide range of financial instruments and financial participants, for example, the derivatives market with carbon futures contracts or carbon trading schemes.

We also acknowledge the generous support from Professor Jiro Akahori, Ritsumeikan University, Japan, and Professor Hideatsu Tsukahara, Seijo University, Japan, to allow us to edit this special issue. In addition, we are grateful to the organizer of the SOB Conference 2020 by the School of Banking, University of Economics Ho Chi Minh City, Vietnam, for providing the open platform for the excellent discussion about these published papers.

In aggregate, the papers in this special issue touch on voluminous aspects of how green and sustainable finance are crucial in the financial market context. We hope that readers will enjoy the set of papers, and the future big ideas from your thoughts that could stem from these papers.

\section{References}

Breitenstein, M., Nguyen, D. K., \& Walther, T. (2021). Environmental hazards and risk management in the financial sector: A systematic literature review. Journal of Economic Surveys, 35(2), 512-538. https://doi.org/10.1111/joes.12411

Dorfleitner, G., Grebler, J., \& Utz, S. (2020). The impact of corporate social and environmental performance on credit rating prediction: North America versus Europe. Journal of Risk, 22(6), 1-33. https://doi.org/10.21314/JOR.2020.437

Kosugi, T. (2010). Assessments of "Greenhouse Insurance": A methodological review. Asia-Pacific Financial Markets, 17(4), 345-363. https://doi.org/10.1007/s10690-009-9111-7

Nasir, M. A., Duc Huynh, T. L., \& Xuan Tram, H. T. (2019). Role of financial development, economic growth \& foreign direct investment in driving climate change: A case of emerging ASEAN. Journal of Environmental Management, 242(March), 131-141. https://doi.org/10.1016/j.jenvman.2019.03. 112

Pham, N. M., Huynh, T. L. D., \& Nasir, M. A. (2020). Environmental consequences of population, affluence and technological progress for European countries: A Malthusian view. Journal of Environmental Management, 260(January), 110143. https://doi.org/10.1016/j.jenvman.2020.110143

Utz, S. (2018). Over-investment or risk mitigation? Corporate social responsibility in Asia-Pacific, Europe, Japan, and the United States. Review of Financial Economics, 36(2), 1-16. https://doi.org/ 10.1016/j.rfe.2017.10.001

Publisher's Note Springer Nature remains neutral with regard to jurisdictional claims in published maps and institutional affiliations. 